\title{
Estimation of High-frequency Wave Radiation Areas on the Fault Plane of the 1995 Hyogo-ken Nanbu Earthquake by the Envelope Inversion of Acceleration Seismograms
}

\author{
Yasumaro Kakehi, ${ }^{1, *}$ Kojiro Irikura, ${ }^{2}$ and Mitsuyuki Hoshiba ${ }^{3}$ \\ 'Seismological and Volcanological Department of Japan Meteorological Agency, \\ Chiyoda-ku, Tokyo 100, Japan \\ ${ }^{2}$ Disaster Prevention Research Institute, Kyoto University, Gokasho, Uji 611, Japan \\ ${ }^{3}$ Meteorological Research Institute, Tsukuba 305, Japan
}

\begin{abstract}
We estimated the high-frequency wave radiation process on the fault plane of the 1995 Hyogo-ken Nanbu earthquake $\left(M_{\mathrm{JMA}}=7.2\right)$, which was a strike slip event along active inland faults, by the envelope inversion of strong-motion acceleration seismograms. The horizontal extent of the region that radiated high-frequency $(2-10 \mathrm{~Hz}$ ) waves is about $45 \mathrm{~km}$, which matches the source region estimated from the inversion of strong-motion displacement waveforms. High-frequency waves were mainly radiated at the periphery of this source region, while a clear gap of radiation was seen in the center. Along the Nojima fault, both high- and low-frequency wave radiation were large. This is explained by the fact that the rupture broke the ground surface here. Highfrequency waves were also radiated at the step-over of faults between Awaji Island and the Kobe area. The step-over is interpreted to have behaved as a geometrical barrier and generated high-frequency waves when ruptured. The radiation of high-frequency waves in the northeastern part from the hypocenter to Kobe was small in the large moment release areas estimated from the displacement waveform inversion, and large at their peripheries. This suggests these high-frequency waves were stopping phases from the subevents corresponding to the large moment release areas. The extent of the source region of high-frequency waves roughly matches that of the heavily damaged areas. We inferred that the strong high-frequency waves that came directly from the source was one of the causes of the heavy damage to low-rise structures.
\end{abstract}

\section{Introduction}

The Hyogo-ken Nanbu earthquake $\left(M_{\mathrm{JMA}}=7.2\right)$ occurred at 2046 on Jan. 16, 1995 (GMT) with its epicenter at the northern edge of Awaji Island of Hyogo Prefecture, Japan. It caused heavy damage such as collapse of houses, buildings and highways, cuts of lifeline systems, and outbreak of fires in the southern part of Hyogo Prefecture, especially in the northern part of Awaji Island and in Kobe City. More than 6,400 people were killed and more than 110,000 buildings were destroyed by the earthquake. The main cause of death was the collapse of houses. This earthquake was of the strike-slip type, and clear surface breaks of fault appeared in the northern part of Awaji Island (Nakata and Yomogida, 1995). This fault is geologically known as the "Nojima fault" (Research Group of Active Faults, 1991). The after-

Received June 20, 1995; Accepted December 6, 1995

${ }^{*}$ To whom correspondence should be addressed. shocks were distributed along active faults from Awaji Island to Kobe. From these facts the Hyogo-ken Nanbu earthquake is estimated to have been the rupture along the Nojima Fault and the active faults of the Rokko fault system.

In this paper, we estimated the radiation process of high-frequency seismic waves, which are directly related to damage to low-rise structures, on the fault plane. It will be of great help to investigate the cause of heavy damage. The investigation of high-frequency radiation is also indispensable in order to understand the dynamic rupture process of earthquakes. Kakehi and Irikura (1996) developed a new method to estimate the high-frequency $(>1 \mathrm{~Hz}) \mathrm{ra}-$ diation process on fault planes from the envelope inversion of acceleration seismograms. They applied it to the $1993 \mathrm{Kushiro-Oki}$ earthquake $\left(M_{\mathrm{JMA}}=7.8\right)$ (Kakehi and Irikura, 1996) and to the 1993 Hokkaido- 
Nansei-Oki earthquake $\left(M_{\mathrm{JMA}}=7.8\right.$ ) (Kakehi and Irikura, 1994), and confirmed the utility of the method. They found that radiation of high-frequency waves was large at the edge of the source region where the rupture stopped for both earthquakes. For the latter, radiation was also large at the place where the aftershock distribution had clear discontinuity. They interpreted it as that the discontinuity behaved as a barrier during the rupture. In this paper, we will apply this envelope inversion method to the 1995 Hyogo-ken Nanbu earthquake and discuss the relation among the high-frequency radiation areas, source rupture process and the heavy damage caused by the earthquake.

\section{Method}

In the 1980's, the waveform inversion technique was successfully introduced for the estimation of detailed source processes (e.g. Kikuchi and Fukao, 1985). Particularly, the usage of near-field data made it possible to determine the rupture process with high accuracy and resolution (e.g. Hartzell and Heaton, 1983; Fukuyama and Irikura, 1986; Mendoza and Hartzell, 1989). However, the frequency coverage of source process studies by the waveform inversion method has been limited up to about $1 \mathrm{~Hz}$.

Zeng et al. (1993) and Cocco and Boatwright (1993) proposed using envelopes of seismograms instead of waveforms to investigate the highfrequency radiation process for which waveform inversion is no longer available, though their definitions of "envelope" are different. The latter obtained the time history of high-frequency radiation, which they called power rate function, from the deconvolution of squared acceleration envelopes. The former estimated, from inversion, the distribution of high-frequency energy radiation intensities on the fault plane of the 1989 Loma Prieta earthquake using the envelopes of the squared high-frequency $(>5 \mathrm{~Hz})$ displacement seismograms as data. Their methods are based on a stochastic assumption that the generation of high-frequency waves on a fault plane is incoherent.

Kakehi and Irikura (1996) also developed a method to use envelopes of acceleration seismograms as inversion data to determine the highfrequency wave radiation process on a fault plane. They used empirical Green's functions to evaluate path and site effects instead of the theoretical approach used by Zeng et al. (1993), because precise evaluation of Green's functions is essential for analysis of high-frequency waves. For example, theoretical calculations using a layered velocity structure can never produce realistic seismic coda waves, which is an important part of the highfrequency seismogram. If you manage to calculate realistic coda waves theoretically, you can not help introducing stochastic assumption on the heterogeneity of media. In this study, their method is used for the analysis. A brief explanation of the method follows.

The synthetic acceleration waveforms of the target event are calculated in the course of the envelope inversion process as explained later. They are calculated from the $\mathrm{NX} \times \mathrm{NW} \times \mathrm{NT}$ summations of aftershock records according to the empirical Green's function method of Irikura (1986) (Fig. 1). The summation is done by the following formulas:

$$
\begin{aligned}
& A(t)=c \cdot \sum_{i=1}^{\mathrm{NX}} \sum_{j=1}^{\mathrm{NW}} w_{i j} \frac{r}{r_{i j}} F_{i j}(t)^{*} a(t), \\
& F_{i j}(t)= \delta\left(t-t_{i j}\right) \\
&+\frac{1}{n^{\prime}} \sum_{k=1}^{(\mathrm{NT}} \sum^{-1) n^{\prime}} \delta\left(t-t_{i j}-\frac{(k-1) \tau_{\mathrm{L}}}{(\mathrm{NT}-1) n^{\prime}}\right), \\
& t_{i j}=\left(r_{i j}-r_{0}\right) / \beta+s_{i j} .
\end{aligned}
$$

Here, $A(t)$ is the synthetic acceleration waveform of the target large event and $a(t)$ is the acceleration waveform of the small event used as an empirical

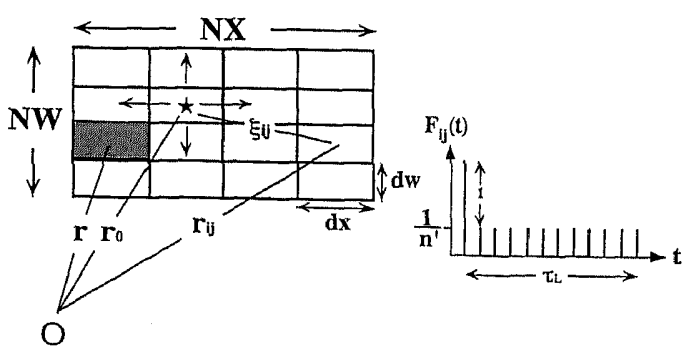

Fig. 1. Left: Schematic fault model for simulating seismograms based on the empirical Green's function method. $r_{0}$ is the hypocentral distance of the large event, $r$ is that of the small event, and $r_{i j}$ is the distance between the $(i, j)$ subfault on the fault plane of the large event and the observation station. Right: The transfer function for correcting the difference in slip velocity time function between the large and small events. 
Green's function. NX $\times$ NW is the number of subfaults the fault plane has been divided into. The size of the subfault is equal to that of the fault plane of the small event. $F(t)$ is the transfer function that takes the scaling relation of slip and rise time between the large and small events into consideration. NT is the ratio of slip and rise time between the large and small events, and $\tau_{\mathrm{L}}$ is the rise time of the large event, $w_{i j}, s_{i j}$, and $r_{i j}$ are the weight, rupture time, and hypocentral distance of $(i, j)$ subfault. $r_{0}$, $r$, and $\beta$ are the hypocentral distance of the large event, that of the small event, and S-wave velocity. $c$ is the stress drop ratio between large and small events.

$w_{i j}$ and $s_{i j}$ are the model parameters to be obtained from the envelope inversion. Positive constraints are given for $w_{i j}$ because sign is meaningless due to the procedure to take running root mean squares for smoothing. It should be noted that this inversion is nonlinear because time variable $s_{i j}$ is included in model parameters and the calculation of root mean squares itself is nonlinear. Therefore, the inversion is linearized and solved iteratively. The inversion process is shown as a flow chart in Fig. 2. First, the observed envelopes are prepared by smoothing the observed acceleration waveforms. Next, the synthetic acceleration waveforms are calculated by the empirical Green's function method based on the model obtained in the previous stage of iteration. Then, envelopes of the synthetic waveforms are calculated by smoothing. The model parameters $w_{i j}$ and $s_{i j}$ are determined so as to make the difference between observed and synthetic envelopes minimum in the least squares sense with positive constraints for $w_{i j}$. Obtained $w_{i j}$ and $s_{i j}$ are regarded as the final solution if convergence is sufficient. Otherwise they are used as the initial model of the next iteration stage. As we are looking at high-frequency accelerations, $w_{i j}$ represents the weight of contribution of each mesh to the high-frequency acceleration envelope anplitudes. Therefore, $w_{i j}$ is called acceleration radiation intensity. The heterogeneity of high-frequency wave radiation on a fault plane is expressed by the distribution of $w_{i j}$. $w_{i j}$ does not have an absolute value. It is a relative value to the intensity of high-frequency wave radiation of the empirical Green's function event.

In the actual analysis, we treated nine subfaults (subfault size corresponds to the source size of the empirical Green's function event) as one mesh for the envelope inversion, as shown later in Figs. 5

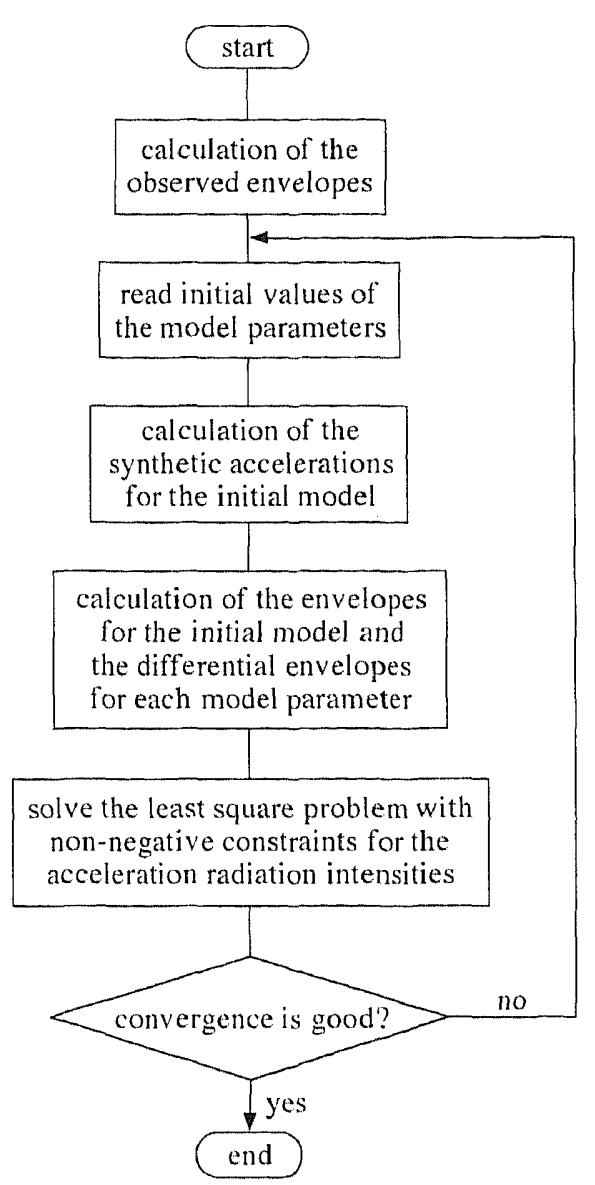

Fig. 2. Flow chart of the envelope inversion.

and 7 , in order to reduce the number of model parameters. The initial values of acceleration radiation intensities are all 1; that is, uniform distribution over the fault plane. The initial values of rupture times of the inversion meshes are for radial rupture propagation with a constant rupture velocity $2.8 \mathrm{~km} / \mathrm{s}(=0.81 \beta, \beta=3.46 \mathrm{~km} / \mathrm{s}$ ). The initial rupture times of the subfaults, which are used to calculate the synthetic acceleration waveforms in the first iteration, are also calculated for the same rupture velocity. When we calculate the synthetic accelerations using the result obtained in the previous iteration, the weight of each mesh is used as the weights of the nine subfaults in it. Rupture time perturbation obtained for a certain inversion mesh in each iteration is added to the rupture times of the nine subfaults included in it in the next iteration, which are used for calculation of the 
synthetic accelerations.

\section{Data}

We used strong ground motion records observed by the Committee of Earthquake Observation and Research in the Kansai Area (CEORKA) and by Japan Meteorological Agency (JMA) for the analysis (Table 1). The locations of the observation stations and the epicenter are shown in Fig. 3. Although $\mathrm{KOB}$ is located on a diluvial upland, it is the most important station because the hypocenteral distance is the shortest and, moreover, the fault plane is estimated to lie beneath it from the aftershock distribution shown later. Stations in the Osaka basin

Table 1. List of stations used in this study.

\begin{tabular}{lcccc}
\hline Name & Lat. $\left(^{\circ}\right)$ & Long. $\left({ }^{\circ}\right)$ & $\begin{array}{c}\text { Seismo- } \\
\text { graph }\end{array}$ \\
\hline MKT & 34.680 & 135.572 & vel. & CEORKA \\
ABE & 34.636 & 135.519 & vel. & CEORKA \\
SAK & 34.564 & 135.469 & vel. & CEORKA \\
CHY & 34.439 & 135.659 & vel. & CEORKA \\
KOB & 34.688 & 135.180 & acc. & JMA \\
OSA & 34.678 & 135.522 & acc. & JMA \\
OKA & 34.658 & 133.918 & acc. & JMA \\
MZH & 35.448 & 135.320 & acc. & JMA \\
MRT & 33.248 & 134.180 & acc. & JMA \\
\hline
\end{tabular}

such as OSA, MKT, ABE, and SAK are relatively close to the hypocenter, but their records are affected by the site effects due to soft soil sediments. Although their site effects were incorporated in the synthetic waveforms by using the empirical Green's functions, the weights of these stations in the inversion should be smaller than that of $\mathrm{CHY}$, which is located on a rock site. Stations such as OKA, MZH, and MRT are important in spite of their large epicentral distances considering the azimuthal distribution of stations. Especially, MRT and $\mathrm{MZH}$, which are located in the direction of the southwestward and northeastward rupture propagations, respectively, can be good constraints on the directivity or source duration. The seismographs of the CEORKA and JMA stations are velocity type and acceleration type, respectively. As for the CEORKA stations, accelerations obtained from the numerical differentiation of velocity records were used for the analysis. The acceleration waveforms were bandpass filtered between 2.0 and $10.0 \mathrm{~Hz}$. Figure 4 shows the band-pass filtered observed acceleration waveforms of the 1995 Hyogo-ken Nanbu earthquake.

Table 2 shows the aftershocks used as the empirical Green's function events. Basically, accelerations from the mainshock at each station were synthesized from three aftershock records, each of

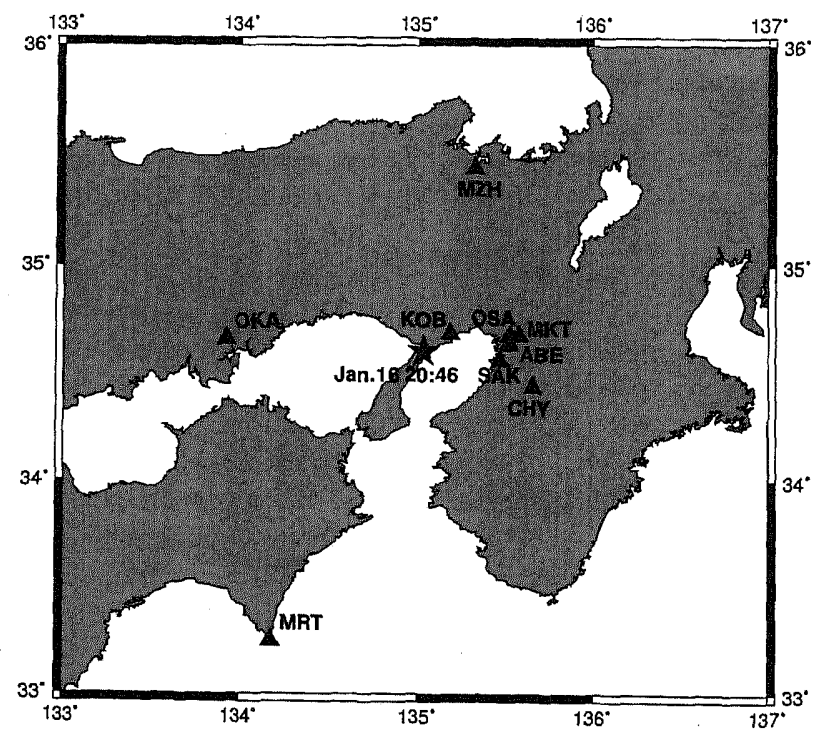

Fig. 3. Locations of the epicenter of the 1995 Hyogo-ken Nanbu earthquake and the stations used in this study. 

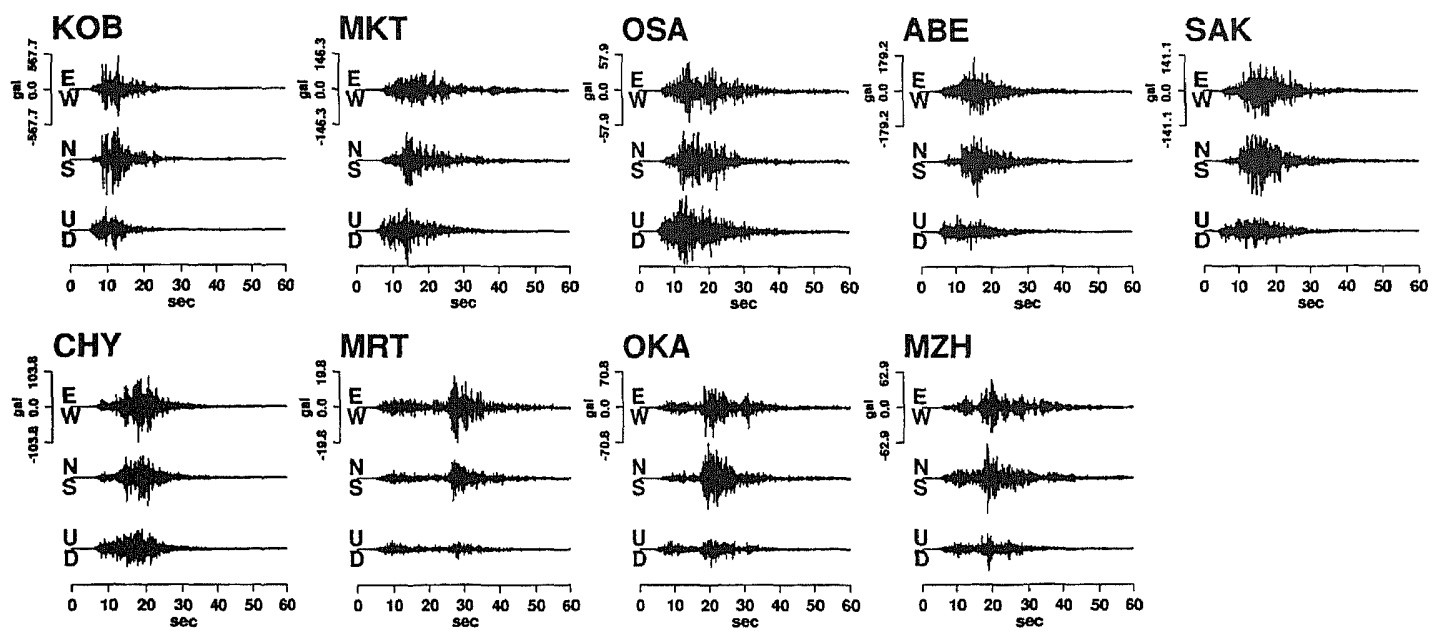

Fig. 4. The observed acceleration waveforms of the Hyogo-ken Nanbu earthquake. They were band-pass filtered between 2.0 and $10.0 \mathrm{~Hz}$.

Table 2. Aftershocks used as empirical Green's functions.

\begin{tabular}{ccccccc}
\hline No. & Origin time (GMT) & Lat. $\left(^{\circ}\right)$ & Long. $\left(^{\circ}\right)$ & Depth $(\mathrm{km})$ & $M_{\text {JMA }}$ & $c$ \\
\hline 1 & 1995 Jan.16, 2128 & 34.523 & 134.913 & 11 & 4.8 & 1.7 \\
2 & 1995 Jan.16, 2200 & 34.473 & 134.860 & 11 & 4.4 & 1.7 \\
3 & 1995 Jan.16, 2330 & 34.578 & 135.001 & 10 & 4.5 & 1.9 \\
4 & 1995 Jan.17, 2358 & 34.587 & 135.001 & 10 & 4.7 & 1.5 \\
5 & 1995 Jan.17, 0405 & 34.688 & 135.172 & 15 & 4.7 & 1.4 \\
6 & 1995 Jan.17, 2150 & 34.683 & 135.170 & 14 & 4.5 & 0.92 \\
7 & 1995 Jan.22, 1533 & 34.555 & 134.952 & 9 & 4.1 & 1.7 \\
\hline
\end{tabular}

which was used to cover the southwestern part, central part, and northwestern part of the fault plane, respectively (shown later in Fig. 7). The exception is MRT, where only the aftershock in the southwestern part was recorded. However, we judged it was no problem to use one aftershock record for the whole fault plane because the epicentral distance of MRT $(170 \mathrm{~km})$ is much larger than the source region size. The relative locations of the empirical Green's function events to the fault plane are shown later in Fig. 7.

\section{Fault Plane Model}

Figure 5 is the aftershock distribution from Jan. 190700 to Jan. 271459 (GMT) relocated by Research Center of Earthquake Prediction of Disaster Prevention Research Institute, Kyoto University. We used a rectangular fault plane of $56.1 \mathrm{~km} \times 19.8 \mathrm{~km}$, which covers the aftershock distribution, for the envelope inversion. It should be noted that this fault plane is larger than the actual source region of seismic wave radiation considering the southwestward and northeastward extension of aftershock activities during the 10 days after the mainshock. Referring to the teleseismic body wave analysis of Kikuchi (1995), we adopted $233^{\circ}$ and $85^{\circ}$ for strike and dip angles of the fault plane, respectively. These angles coincide with the aftershock distribution very well.

This study is a preliminary one assuming a single fault plane model. Actually, the seismic fault is considered to consist of plural planes, which is estimated from the geodetic data (Tada et al., 1995) and from the particle motion analysis of near-source seismograms (Sekiguchi et al., 1996, 1997). Still, analysis based on a simple fault model is very useful. For example, if large high-frequency wave radiation is found in an area where the existence of a step-over 
Jan. 19 07:00 - Jan. 27 14:59
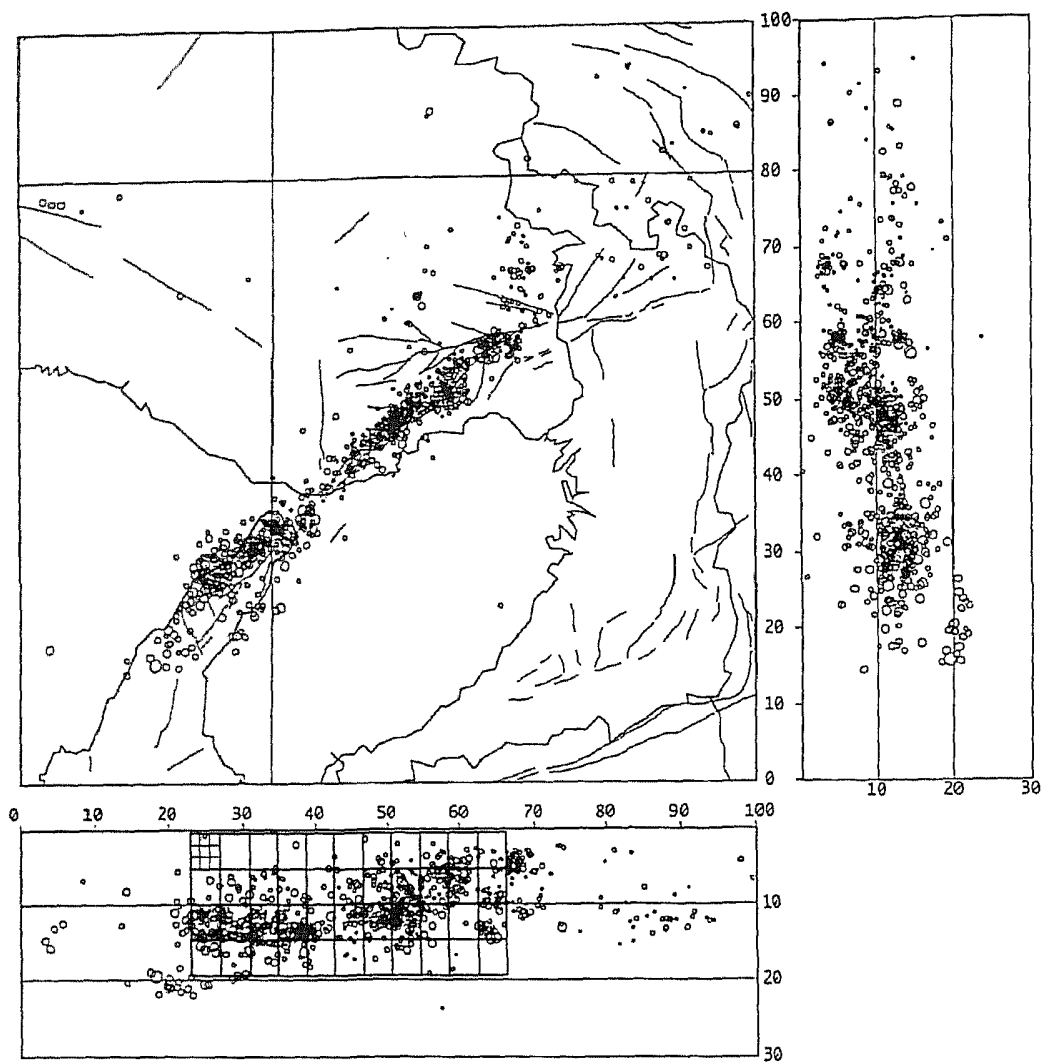

\begin{tabular}{|c|}
\hline MAGNITUDE \\
\hline 05.0 \\
\hline 04.0 \\
\hline 03.0 \\
\hline 02.0 \\
\hline .1 .0 \\
\hline
\end{tabular}

Fig. 5. The aftershock distribution (determined by Research Center of Earthquake Prediction of Disaster Prevention Research Institute, Kyoto University) and the fault plane used for the envelope inversion. The small squares in the upper-left mesh on the fault plane correspond to the source size of the empirical Green's function event.

of fault planes is suspected, it will be strong support for the existence of said step-over. Actually, as is shown later, large high-frequency wave radiation was found at the step-over pointed out by Sekiguchi et al. (1997) for the 1995 Hyogo-ken Nanbu earthquake. Of course, further analysis based on a realistic model composed of plural fault planes will be necessary in order to obtain a more strict result. This is possible when the final fault model is established, referring to various information such as geological surveys, geodetic studies, particle motion analyses of near-source seismograms, waveform inversions, detailed relocation of aftershocks, and so on.

The fault plane is divided into subfaults for the analysis. This subfault size coincides with the source size of the empirical Green's function event. We estimated the source sizes of the aftershocks from their corner frequencies using the formula of Brune (1970, 1971): 

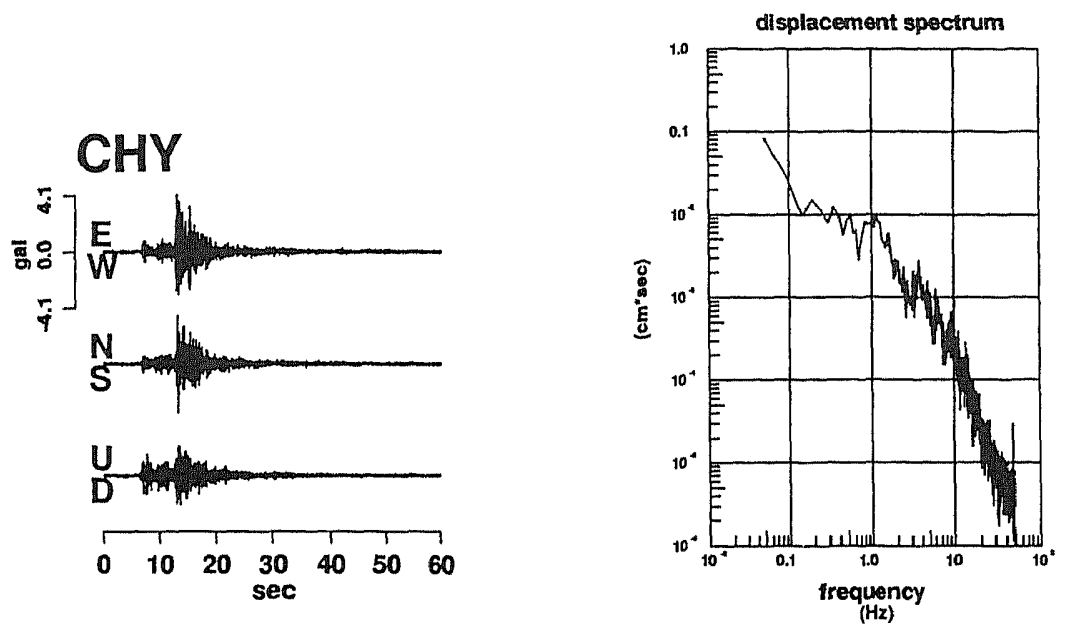

Fig. 6. An example of the aftershock acceleration waveforms and the displacement spectrum. The spectrum is calculated from the vectorial summation of three-component spectra. The record of the No. 5 aftershock at CHY.

$$
r=\frac{0.373 \beta}{f_{\mathrm{c}}}
$$

Here, $r$ is the radius of the circular fault, $\beta$ is the $S$-wave velocity, and $f$ is the corner frequency. As the corner frequencies of the aftershocks we selected are almost the same, it was possible to use a common subfault size for the three different fault plane parts with different Green's function events. The average corner frequency of the aftershocks for all the stations was $1.3 \mathrm{~Hz}$. Figure 6 shows an example of the displacement spectrum of an aftershock. We modified Eq. (4) for a square source using $L=$ $\sqrt{\left(\pi r^{2}\right)}$ and obtained $L=1.7 \mathrm{~km}$, where $L$ is the length of the square source. In the actual analysis, we used a subfault area of $1.7 \mathrm{~km} \times 1.65 \mathrm{~km}$. It follows that the inversion fault plane is composed of $33 \times 12$ subfaults. We used $11 \times 4$ meshes for the inversion, each of which is composed of $3 \times 3$ subfaults, to reduce the number of model parameters. In Fig. 5, the fault plane, inversion mesh, and subfault are also shown on the EW cross section of aftershock distribution. In Fig. 7, the locations of the aftershocks projected on the inversion fault plane are shown.

\section{Analysis}

As mentioned above, the inversion fault plane was divided into $\mathrm{NX} \times \mathrm{NW}$, equaling $33 \times 12$ subfaults. We used NT $=8$ and $\tau_{\mathrm{l}}=3.2 \mathrm{~s}$ after some trial and

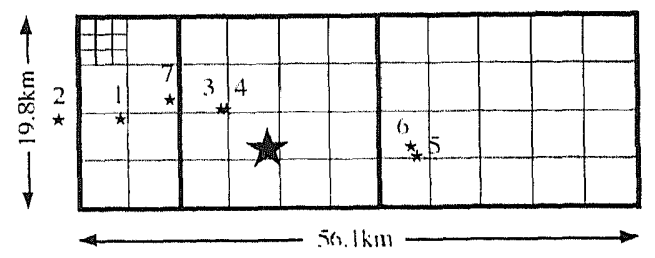

Fig. 7. The southwestern, central, and northeastern parts of the fault plane. They correspond to the southwestern 2 (horizontal) $\times 4$ (vertical) meshes, the central $4 \times 4$ meshes, and the northeastern $5 \times 4$ meshes, respectively. Three different aftershocks are used to cover these three parts to calculate synthetic acceleration waveforms of the mainshock at all stations except MRT. The hypocenters of the aftershocks used as the empirical Green's function events (small stars) are projected on the plane. The numbers correspond with those in Table 2. The large star is the hypocenter of the mainshock.

error. Stress drop ratio between large and small events $\left({ }^{\prime}\right)$ are different depending on aftershocks. To determine the values of $c$, first we made synthetic accelerations for the initial model, which is explained later, using only the aftershock records in the central part of the fault plane. We estimated $c$ for an event in the central part from matching the amplitudes of 
the synthetic accelerations to those of the observed accelerations. Once the $c$ of the aftershock in the central part was fixed, we were able to determine the $c$ values for any events in other parts by matching the high-frequency spectral level of acceleration from the events in other parts to that from the event in the central part. In Table 2, the values of $c$ determined in this way are also listed.

We performed correction of the $Q$ effect in the course of making synthetic accelerations. Hoshiba (1993) estimated the scattering $Q$, intrinsic $Q$, and total $Q$ values for the areas around various stations in Japan. We used $Q=100 f$ ( $f$ is frequency in $\mathrm{Hz}$ ) for correction referring to the total $Q$ value around the Wakayama station closest to the source region of the 1995 Hyogo-ken Nanbu earthquake.

As the initial model for the envelope inversion, we used the uniform acceleration radiation intensities and the rupture times for the radial rupture propagation with $2.8 \mathrm{~km} / \mathrm{s}(=0.81 \beta, \beta=3.46 \mathrm{~km} / \mathrm{s})$. First, we tried the envelope inversion assuming the hypocenter determined by Research Center of Earthquake Prediction of Disaster Prevention Research Institute, Kyoto University (34.604 , $135.034^{\circ}$, depth $=17.3 \mathrm{~km}$ ) for the rupture starting point. We found a shallower starting point provided better results after some trials. Therefore, we adopted a depth of $14.4 \mathrm{~km}$ as the starting point in the inversion. This depth is almost the same as the $14 \mathrm{~km}$ depth determined by JMA. We used a running root mean square window with a $2.0 \mathrm{~s}$ width to smooth acceleration waveforms.

\section{Results and Discussion}

Figure 8 shows a comparison of the observed and synthetic envelopes for the initial model. The readers will find underestimation at $\mathrm{KOB}$ and overestimations at SAK and OKA. At MRT, the duration of the synthetic envelope is longer than that of the observed, especially on the NS-component. In the envelope inversion, both the observed and synthetic envelopes are normalized with the maximum value of the observed envelopes to make the weights of all the stations equal except $\mathrm{KOB}$ and $\mathrm{CHY}$. For $\mathrm{KOB}$ and $\mathrm{CHY}$ we used weights twice as large as those for the other stations, considering the former is the closest to the hypocenter and the latter is located on a rock site. After five iterations, we obtained the final solution. Figure 9 shows a comparison of the observed and synthetic

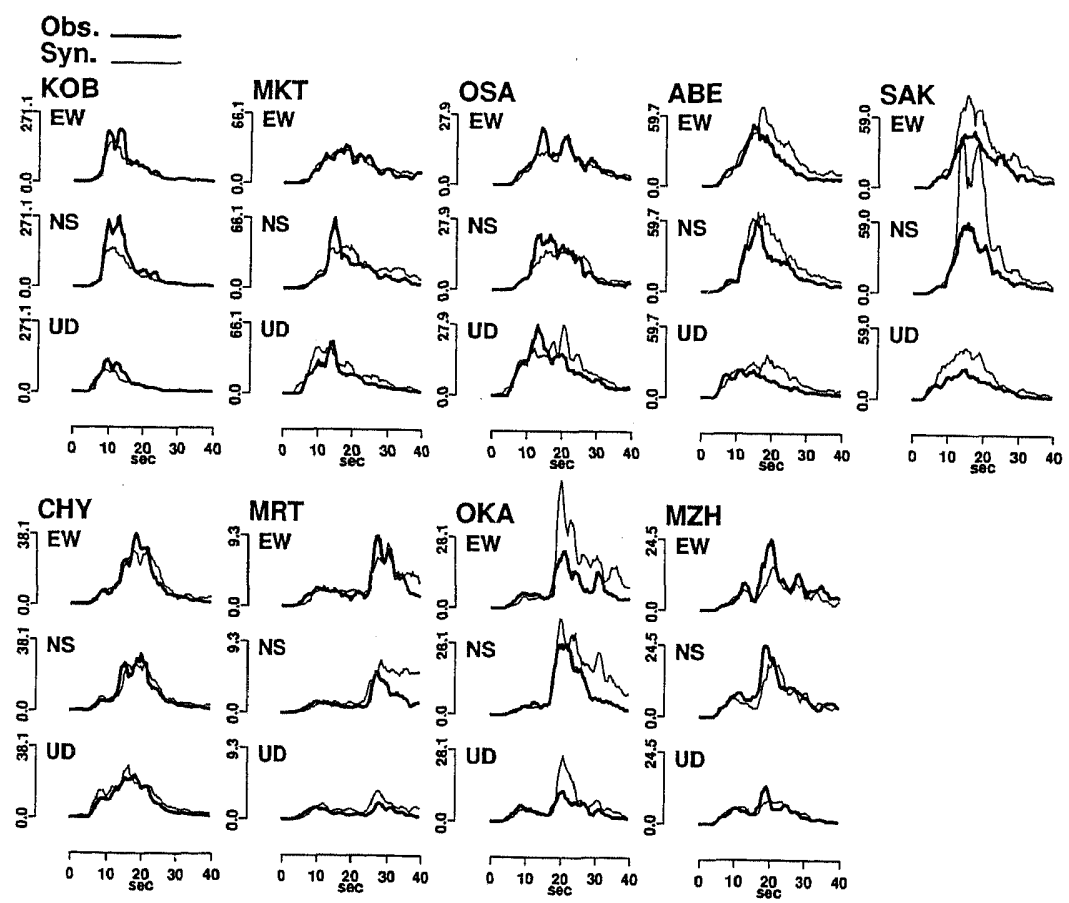

Fig. 8. Comparison of observed and synthetic envelopes for the initial model. 


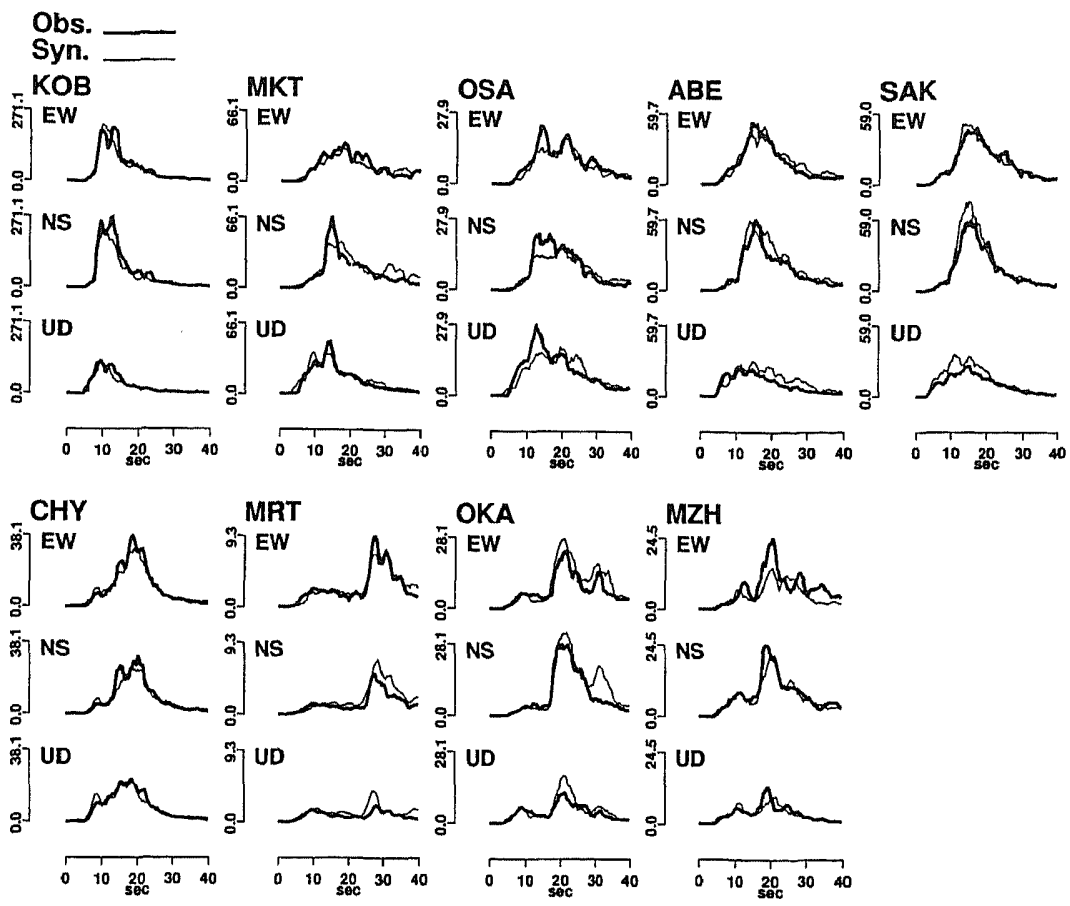

Fig. 9. Comparison of observed and synthetic envelopes for the final solution.

envelopes for the final solution. The match is very good. The amplitudes at KOB, SAK, and OKA and the duration at MRT are reproduced very well. The residual was reduced to $34 \%$ of that for the initial model.

Figure 10 shows the final solution of the acceleration radiation intensity (Fig. 10 (a)) and rupture time distributions (Fig. 10 (b)). The extent of the effective source region that radiated highfrequency waves from 2 to $10 \mathrm{~Hz}$ is about $45 \mathrm{~km}$ horizontally (from about $15 \mathrm{~km}$ southwest of the hypocenter to about $30 \mathrm{~km}$ northeast of the hypocenter) as represented by the arrow in the figure. It took only about $10 \mathrm{~s}$ for the rupture of this effective region. For comparison, the moment release distribution from the inversion of strong-motion displacement waveforms (Sekiguchi et al., 1997), which expresses the distribution of low-frequency wave radiation, is shown in Fig. 10 (c). In their waveform inversion, the fault is assumed to consist of three planes, one on the Awaji Island side and two on the Kobe side. Though a step-over is assumed between the Awaji and Kobe planes, they merge at the starting point marked with a star. The extent of the effective source region estimated from the low-frequency waveform inversion is almost the same as that estimated from the high-frequency envelopes.

The high-frequency waves were radiated at the area extending aslant from just below the Nojima fault to the bottom of the fault plane (A, B, and $\mathrm{C}$ in Fig. 10 (a)), just below Kobe City (D in the same figure), and at the deepest part below Kobe City ( $E$ in the same figure). They are located at the periphery of the effective source region except B. High-frequency wave radiation at the periphery of the source like this can be basically interpreted as the stopping phase (Madariaga, 1976). Similar result was reported by Kakehi and Irikura (1996) for the 1993 Kushiro-Oki earthquake $\left(M_{\text {JMA }}=7.8\right)$. The large high-frequency wave radiation areas denoted by $\mathrm{C}$ and $\mathrm{E}$ are located close to the boundaries of the large moment release areas found by Sekiguchi et al. (1997). Zeng et al. (1993) obtained a similar result for the distribution of low- and high-frequency wave radiation on the fault plane in their analysis of the 1989 Loma Prieta earthquake $\left(M_{S}=7.1\right)$. It can be interpreted as the stopping phases from the subevents corresponding to the large moment release areas.

Vol. 44, No. 5, 1996 
(a)

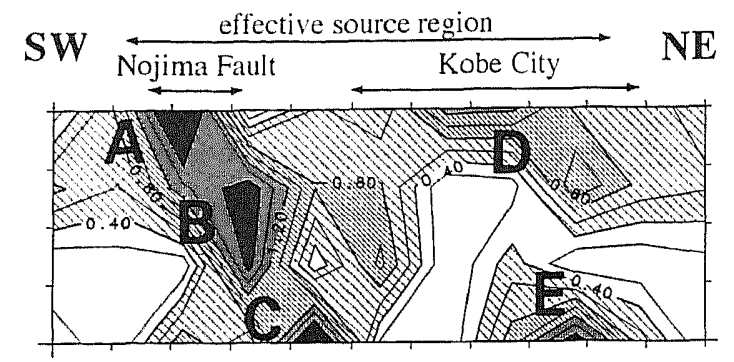

(b)

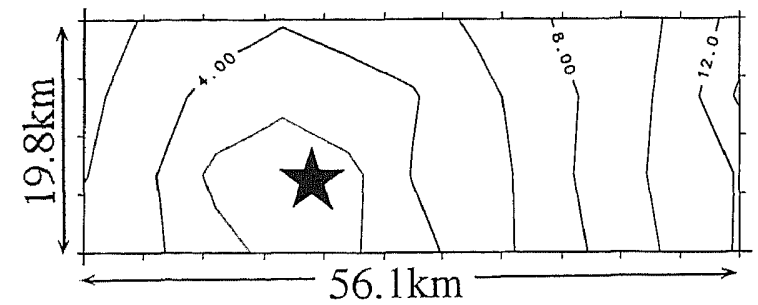

(c)

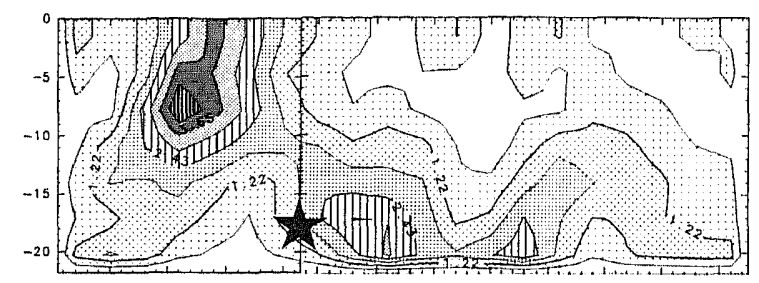

(d)

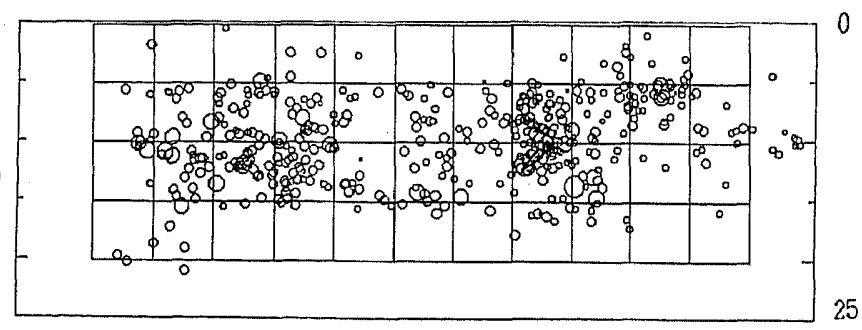

Fig. 10. (a) Obtained acceleration radiation intensities. (b) Obtained rupture time distribution (in s). (c) The moment release distribution obtained from the inversion of strong-motion displacement waveforms (Sekiguchi et al., 1997). The contours show the moment release of each inversion mesh (in N.m). (d) A cross section of the aftershock distribution with the inversion meshes used in the envelope inversion.
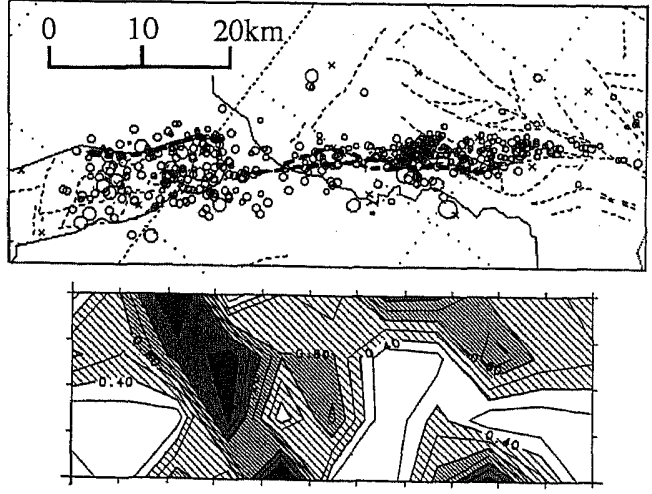

Fig. 11. Comparison between the obtained acceleration radiation intensity distribution and the active fault traces with the aftershock distribution (Jan. 17, 0100-Jan. 17, 1500, 1995 (GMT)), which was determined by Research Center of Earthquake Prediction of Disaster Prevention Research Institute, Kyoto University. The active fault traces in the effective source region are drawn with bold-type dotted lines. 
Both low- and high-frequency wave radiation are large on the Nojima fault (A in Fig. 10). The reason for the large slip is that the rupture broke the ground surface here. Mikumo it al. (1987) found this phenomenon by the numerical simulations of the dynamic rupture process. Hanks (1974) reported that high-frequency waves are radiated when the rupture breaks the ground surface and named it breakout phase. This explains that high-frequency wave radiation is also large here.

The large high-frequency wave radiation denoted by $B$ is located at the step-over of the fault planes between Awaji Island and the Kobe area (Figs. 10 and (1). The high-frequency radiation at the stepover is interpreted as follows: the pre-existing jump of the active fault behaved as a geometrical barrier and high-frequency waves were radiated when the rupture jumped from the first fault plane to the
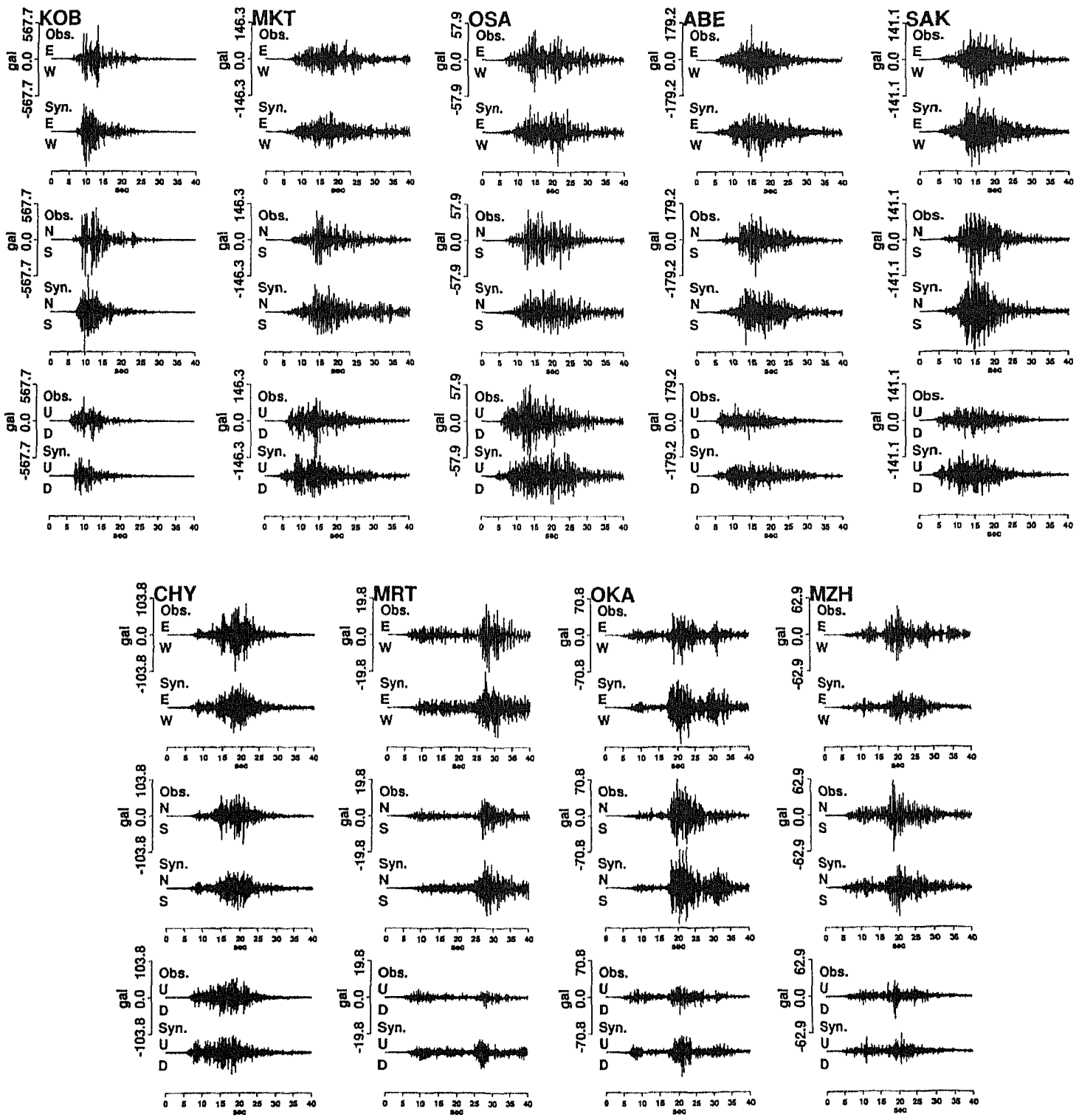

Fig. 12. Comparison of observed and synthetic acceleration waveforms for the final solution.

Vol. 44, No. 5, 1996 
other. Kakehi and Irikura (1994) found large highfrequency excitation at the place with a clear aftershock distribution discontinuity for the 1993 Hokkaido-Nansei-Oki earthquake, too.

Figure 10 (d) shows a cross section of the aftershock distribution with the meshes for the envelope inversion. The focal depths are concentrated between 5 and $10 \mathrm{~km}$. There is a zone of low aftershock density in the center of the distribution. On the Awaji side, many aftershocks occurred in the area with large high-frequency radiation ( $B$ in the Fig. 10 (a)), while on the Kobe side, high aftershock activity was seen in the area with low radiation of high-frequency waves (between D and E). It seems difficult to find a clear relation between the aftershock and high-frequency radiation distributions.

The extent of the region of high-frequency wave radiation roughly coincides with the area of large damage in the northern part of Awaji Island and in the Kobe area. In particular, the high-frequency motions generated in the shallow area beneath Kobe City are estimated to be directly related to the heavy damage. This means that seismic waves between 2 and $10 \mathrm{~Hz}$ where the characteristic period of low-rise structures lies were already large at their generation on the fault plane. This was one of the causes of the heavy damage to low-rise structures in this region. It should be noted that it is not the only cause, but one of the causes. The amplification by the soft soil can be another cause. Maybe the heavy damage was the result of the combination of the source and site effects, but in this paper we concentrate on the source process and do not discuss which factor was stronger. Figure 12 shows a comparison of the observed and synthetic acceleration waveforms for the final solution. Agreement between them is very good, which indicates the utility of the method.

We thank the Committee of Earthquake Observation and Research in the Kansai Area for providing us with strong ground motion data. We thank Earthquake Prediction Research Center of Disaster Prevention Research Institute, Kyoto University, for allowing us to use their aftershock distribution figures. The aftershock distribution is drawn using the win program (Urabe and Tsukada, 1992). We thank Mr. Jorge Aguirre and Miss Haruko Sekiguchi for helping us to make figures. We thank the two reviewers for giving a lot of useful advice. It greatly improved this manuscript.

\section{REFERENCES}

Brune, J. N., Tectonic stress and the spectra of seismic shear waves from earthquakes, $J$. Geophys. Res., 75, 4997-5009, 1970.

Brune, J. N., Correction, J. Geophys. Res., 76, 5002, 1971.

Cocco, M. and J. Boatwright, The envelopes acceleration time histories, Bull. Seismol. Soc. Am., 83, 1095-1114, 1993.

Fukuyama, E. and K. Irikura, Rupture process of the 1983 Japan Sea (Akita-Oki) earthquake using a waveform inversion method, Bull. Seismol. Soc. Am., 76, 16231640, 1986.

Hanks, T. C., The faulting mechanism of the San Fernando earthquake, J. Geophys. Res., 79, 1215-1229, 1974.

Hartzell, S. H. and T. H. Heaton, Inversion of strong ground motion and teleseismic waveform data for the fault rupture history of the 1979 Imperial Valley, California, earthquake, Bull. Seismol. Soc. Am., 73, 1553-1583, 1983.

Hoshiba, M., Separation of scattering attenuation and intrinsic absorption in Japan using the multiple lapse time window analysis of full seismogram envelope, $J$. Geophys. Res., 98, 15809-15824, 1993.

Irikura, K., Prediction of strong acceleration motion using empirical Green's function, Proc. 7 th Jpn. Earthq. Eng., 8, 37-42, 1986.

Kakehi, Y. and K. Irikura, High frequency radiation process during earthquake faulting--envelope inversion of acceleration seismograms from the 1993 HokkaidoNansei-Oki earthquake, Bull. Seismol. Soc. Am., submitted.

Kakehi, Y, and K. Irikura, Estimation of high frequency wave radiation areas on the fault plane by the envelope inversion of acceleration seismograms, Geophys. J. Int., 125, 892-900, 1996.

Kikuchi, M., Source process of the Kobe earthquake of January 17, 1995, Chishitsu News, 486, 12-15, 1995 (in Japanese).

Kikuchi, M. and Y. Fukao, Iterative deconvolution of complex body waves from great earthquakes-the Tokachi-Oki earthquake of 1968, Phys. Earth Planet. Inter., 37, 235-248, 1985.

Madariaga, R., Dynamics of an expanding circular fault, Bull. Seismol. Soc. Am., 66, 639-666, 1976.

Mendoza, C. and S. H. Hartzell, Slip distribution of the 19 September 1985 Michoacan, Mexico, earthquake: Near-source and teleseismic constraints, Bull. Seismol. Soc. Am., 79, 655-669, 1989.

Mikumo, T., K. Hirahara, and T. Miyatake, Dynamical fault rupture processes in heterogeneous media, Techtonophysics, 144, 19-36, 1987. 
Nakata, T. and K. Yomogida, Surface fault characteristics of the 1995 Hyogo-ken Nanbu earthquake, J. Nat. Disast. Sci., 10, 1-10, 1995.

Research Group for Active Faults of Japan, Active Faults in Japan-Sheet Maps and Inventories, the University of Tokyo Press, Tokyo, 1991 (in Japanese).

Sekiguchi, H., K. Irikura, T. Iwata, Y. Kakehi, and M. Hoshiba, Determination of the location of faulting beneath Kobe during the 1995 Hyogo-ken Nanbu, Japan, earthquake from near-source particle motion, Geophys. Res. Lett., 23, 387-390, 1996.

Sekiguchi, H., K. Irikura, T. Iwata, Y. Kakehi, and M. Hoshiba, Minute locating of faulting beneath Kobe and the waveform inversion of the source process during the 1995 Hyogo-ken Nanbu, Japan, earthquake using strong ground motion records, J. Phys. Earth, 44, 473-487, 1996.

Tada, T., M. Hashimoto, T. Sagiya, and S. Ozawa, A geodetical fault model of the 1995 Kobe earthquake, Chikyu Monthly. Special Issue on the 1995 Hyogo-ken Nanbu earthquake, pp. 136-140, 1995 (in Japanese).

Urabe, $\mathrm{T}$ and $\mathrm{S}$. Tsukada, win-A workstation program for processing waveform data from microearthquake networks, Abstr. Seismol. Soc. Jpn., 2, 331, 1992 (in Japanese).

Zeng, Y., K. Aki, and T. Teng, Mapping of the highfrequency source radiation for the Loma Prieta earthquake, California, J. Geophys. Res., 98, 11981-11993, 1993. 